\title{
RECORDING PREHISTORIC ROCK-ART : A THREE DIMENSIONAL APPROACH
}

\author{
Paul Bryan \\ Metric Survey Team \\ English Heritage \\ 37 Tanner Row \\ York \\ YO1 6WP \\ UK \\ paul.bryan@english-heritage.org.uk \\ http://www.english-heritage.org.uk/metricsurvey \\ http://www.heritage3d.org
}

\begin{abstract}
The Northumberland and Durham Rock Art Project (NADRAP), a three year English Heritage funded project formally completed in July 2008, set out to pilot a methodology for creating an index of around 1,500 known rock art panels located across two counties of the north-east of England. Principally using around 60 volunteers recruited from the local community, this would provide a georeferenced dataset which included both drawn and photographic records of the motifs represented. It also sought to test, compare and make recommendations against a number of different rock-art recording techniques, including both laser and image based approaches. The latter used a new, lower-cost recording approach based on using 'off-the-shelf' digital cameras, stereo-photography and new photogrammetric processing software by Topcon - PI-3000.
\end{abstract}

As well as highlighting the recording work undertaken by the project volunteers, this paper will describe the methodological development and how, through training and education, the volunteers have come to terms with using it. Also it will focus on the data dissemination aspects which led to the launch in July 2008 of a new rock-art website entitled England's Rock Art (ERA). Here interested parties, be they rock-art experts or casual visitors, can explore the fascinating detail of England's rock-art, as well as downloading and viewing numerous datasets created by the volunteers, including interactive, 3D models supplied in VRML format. As well as being successfully used within a rock-art context the developed approach to recording, using photogrammetry, has numerous other applications across the heritage sector.

\section{INTRODUCTION}

Within the UK the term 'Rock Art' is generally used to describe prehistoric carvings made on boulders and rock outcrops generally dated to the late Neolithic - early Bronze Age (3500-1500BC). The most commonly found carving is a cup mark, although designs can include rings and grooves forming elaborate patterns - also known as 'cup \& ring' marks. Within England there are approximately 2,400 known panels with over 1,500 located across the two counties of Northumberland and Durham (figure 1). 


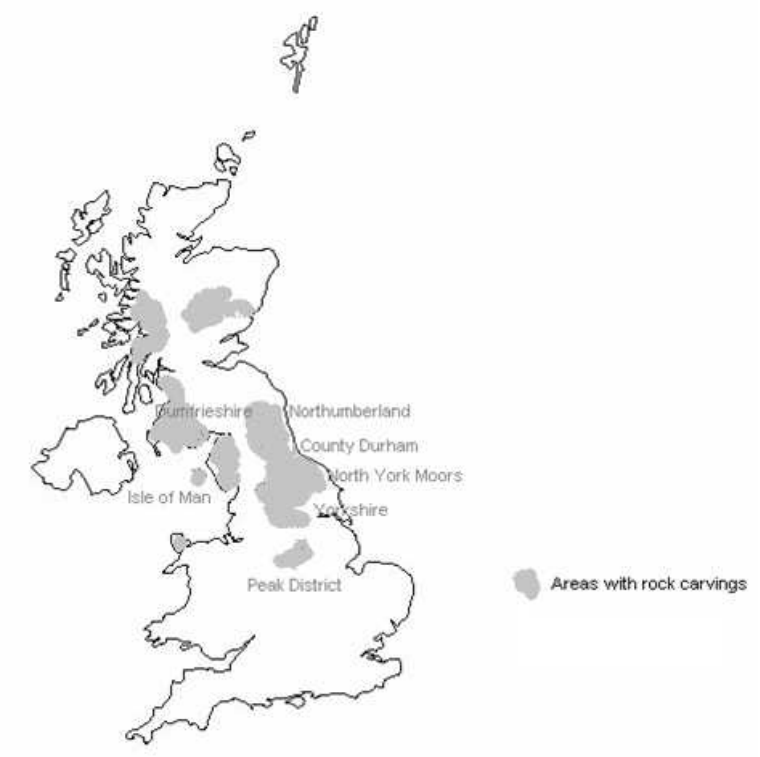

Figure 1. Distribution of Prehistoric Rock-Art across UK (courtesy of Tertia Barnett, RCAHMS)

The recording of both engraved carvings (petroglyphs) and painted images (pictographs) has traditionally been tackled by two-dimensional approaches including:

- conventional \& digital photography - easiest and most convenient method of recording which typically produces excellent 'objective' results but needs the right lighting conditions to pick out the carved detail

- 'rubbings' - enables the recorder to literally 'feel' the features through touch but requires great skill to produce good results and interpretations can be viewed as 'subjective'.

- drawing - an effective method for presenting the carvings but dependant on the skills of the recorder and outputs can again be viewed as 'subjective'.

Although sufficient for documentation purposes neither is able to capture accurately the three-dimensionality of the host rock, where its shape and form may have influenced the original designs that are carved or painted on to the surface.

\section{THE NORTHUMBERLAND AND DURHAM ROCK ART PROJECT (NADRAP)}

The Northumberland and Durham Rock Art Project (NADRAP) was launched in 2004. Originally a two year project, funded by English Heritage in partnership with the County Councils for Northumberland and Durham, it was the pilot for what may become a national project. As noted in the English Heritage Research Agenda 20052010 [1] "Its key aim is to recruit and train volunteers who will then record all known engravings in Northumberland and County Durham using a standardised methodology. 
The information will then be entered into a specially designed database. The archive will be made available via the internet and will provide a valuable resource for research, conservation and management." (figure 2)

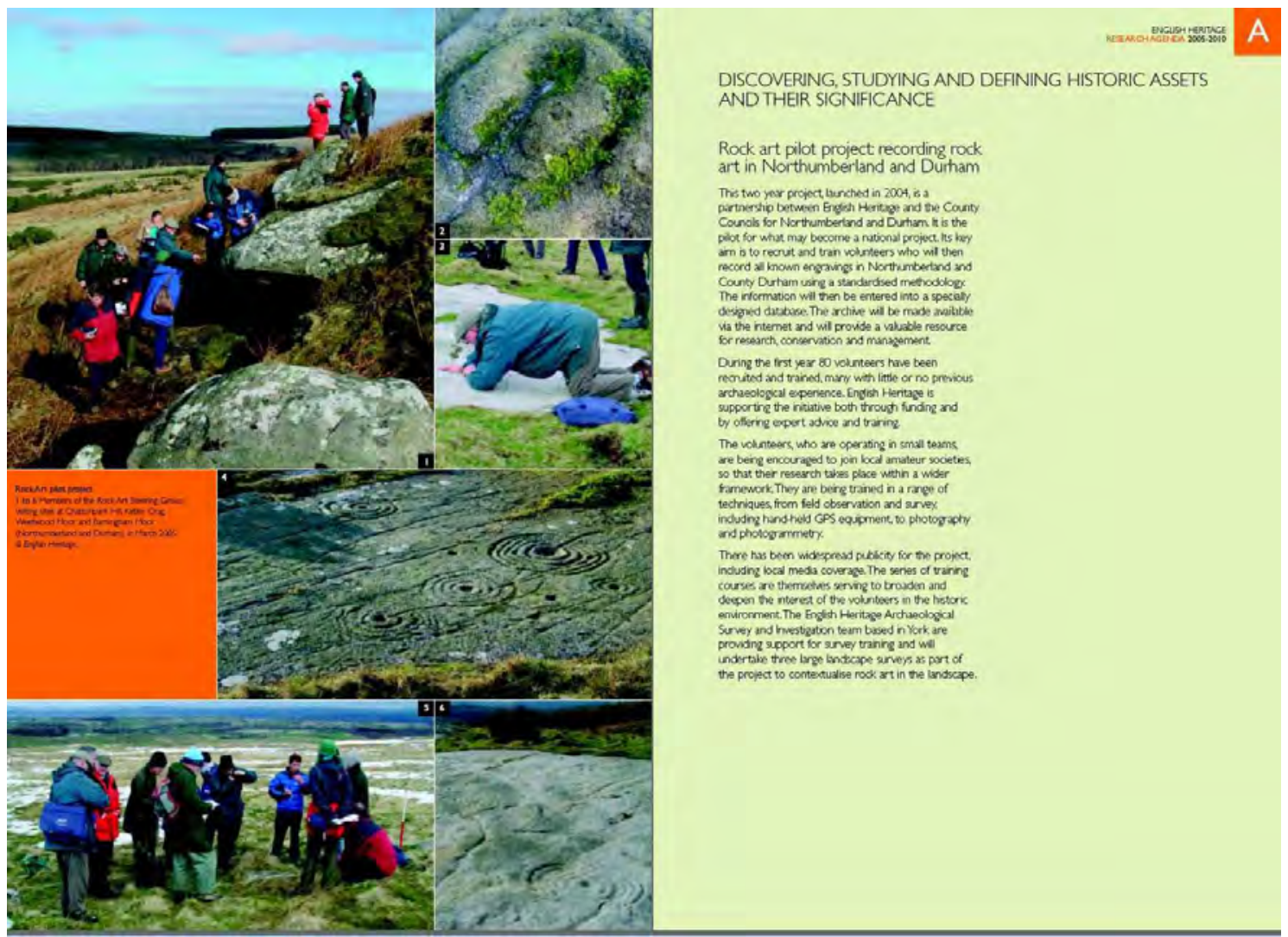

Figure 2. The Northumberland and Durham Rock Art Project (NADRAP) as described in the English Heritage Research Agenda 2005-2010

\section{Recording techniques}

As well as harnessing the knowledge, enthusiasm and diverse skills of over 100 local volunteers, alongside recording training provided by professional specialists from English Heritage, NADRAP also sought to test, compare and make recommendations against a number of different rock-art recording techniques. These ranged from planning individual stones with hand-tapes to surveying entire hillsides using highaccuracy GPS and from interpretative pencil sketches through to high-resolution laser scanning and digital photogrammetry. Both of the latter are very capable of generating high (millimetric) accuracy recordings of rock-art but are typically associated with highend, high-cost application for both the required equipment/software and operation by specialist, highly-trained personnel. Therefore NADRAP took the opportunity to test a new photogrammetric approach based on 'off-the-shelf' consumer grade digital cameras, stereo-photography and new lower-cost photogrammetric processing software by Topcon - PI-3000. 


\section{PHOTOGRAMMETRIC RECORDING}

Photogrammetry was developed over 150 years ago and is officially defined as:

The science, and art, of determining the size and shape of objects as a consequence of analysing images recorded on film or electronic media (Fryer, 1996)

It is typically based upon the capture of photography or its modern, digital equivalent. Although some basic measurement can be obtained from a single two dimensional image, it is the capture of a pair of overlapping images - the stereo-pair that forms the building block for all outputs and along with some form of scale creates the three-dimensional view of the object from which later measurement and data extraction can take place.

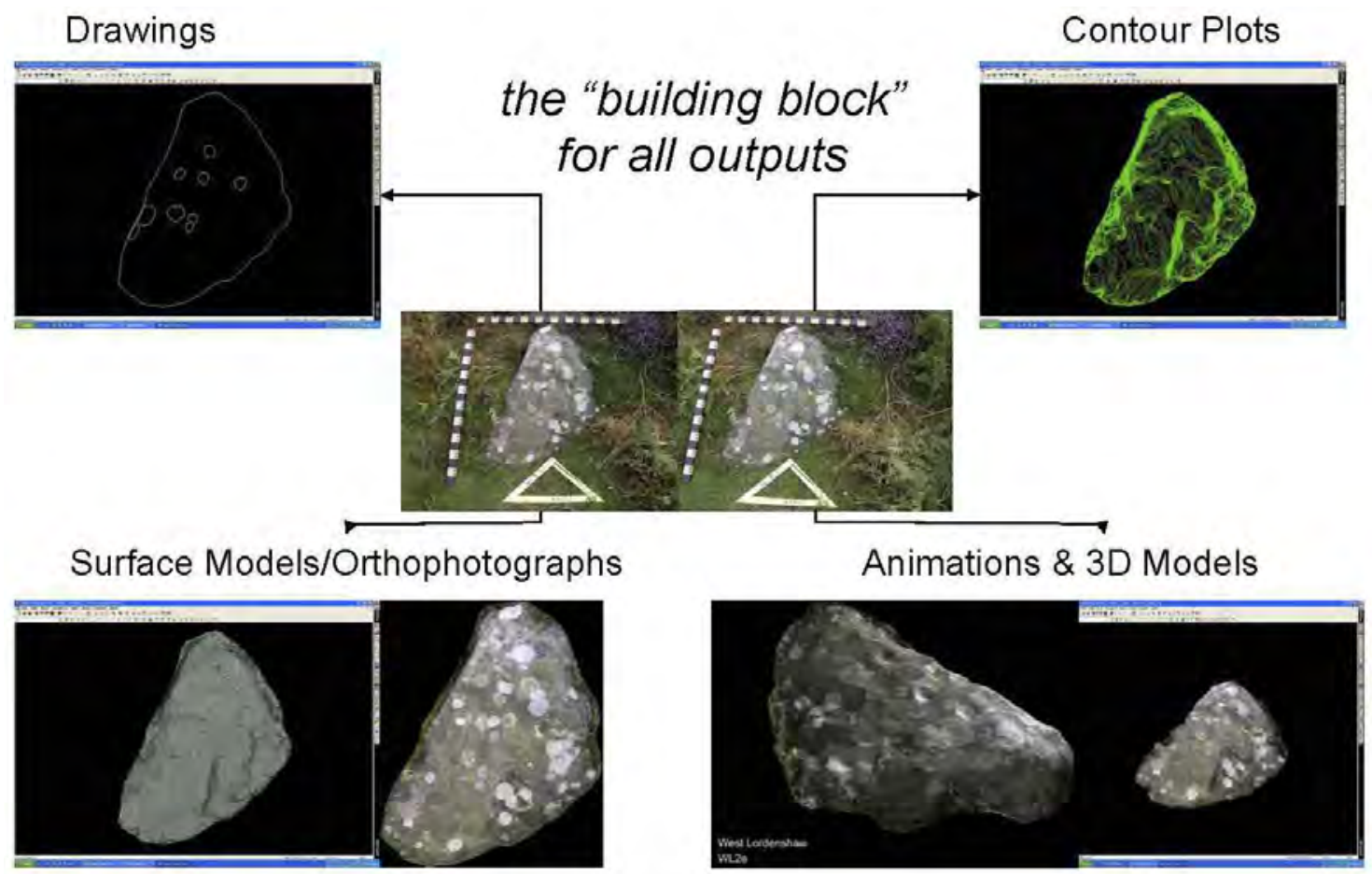

Figure 3. The stereo-pair and possible, derived outputs

For many rock-art sites, a single stereo-pair is all that is required to capture the carved detail visible on the rock surface and provide a suitable basis for later photogrammetric processing so as to supply a variety of outputs including drawings, contour plots, surface models, orthophotographs, animations and 3D models. (Figure 3). Suitable images can be acquired using a handheld camera although a tripod is usually used to provide sharp, well exposed imagery particularly in low light conditions. These days a wide variety of consumer-grade digital cameras exist that are usually equipped with a variable zoom and auto-focus lens [2]. Although suitable for general, narrative recording they are not ideal for photogrammetry, where the focal length is typically fixed and precisely determined. However, their photogrammetric application is rapidly 
developing given both their increasingly high image resolutions, currently between 8-12 MPixels, and the development of 'do-it-yourself' camera calibration software packages which derive all the necessary camera and lens parameters required for successful processing.

\section{Camera Calibration}

Existing research has already suggested 5MPixels to be an appropriate, entry-point for 'low-cost' photogrammetry [3] whilst also demonstrating the geometric consistency and stability of consumer-grade cameras such as the Nikon Coolpix 5400 used by NADRAP [4]. Although such research also demonstrated potential data accuracies of up to $\pm 1.5 \mathrm{~mm}$, photogrammetric recording at this scale typically achieves sub-centimetre accuracy which is generally suitable for most heritage recording applications including rock-art. However in order to achieve this and any higher accuracy levels, as for instance required for decay monitoring, it is prudent to model first the geometric parameters of the chosen camera and lens combination in order to define:

- the precise focal length of the lens at exposure

- lens distortion, both in radial and tangential directions

- the central 'principal point' of the image sensor

- the exact dimensions of the individual pixels making up the sensor.

This collection of parameters is commonly referred to as 'Camera Calibration'. Even though it has traditionally been performed in university laboratories, using multiple image sets of a precisely observed test-wall, it can these days be determined directly by the user using one of the calibration routines that are being included with 'lower-cost' photogrammetric software such as Photomodeler Scanner, iWitness and Topcon PI3000 (now known as ImageMaster).

\section{Scaling}

The simplest method of scaling each stereo-pair, and by far the easiest to transport to/ from site, is to employ a single scale bar which allows data to be captured, extracted and output to a known scale. Application of additional scale bars in both horizontal and vertical directions (see figure 3) provide a redundancy in measurement and a check on the overall accuracy of any subsequent processing. However, if the object is too large to be captured using a single stereopair then targeted control can be adopted through the temporary application of small targets attached to non-engraved sections of the rock surface using some form of non-destructive adhesive such as clear, silicone bathroom sealant. Ideally these should be observed using a total station theodolite, to provide three-dimensional coordinates for each target, although manual taping and inclusion of scale bars is a less accurate alternative.

\section{Photogrammetric Data Processing}

The majority of photogrammetric processing is these days carried out on Digital Photogrammetric Workstations (DPW). These typically comprise a 3D screen, utilising 
using either passive (polarising) or active (shutter) glasses, a high-end personal computer and specialist processing software such as BAE's SOCET SET and Leica Photogrammetry Suite (LPS). After importing the digital files for each stereo-pair, correctly associating the relevant camera calibration file, removing parallax through digitising common points and entering any scaling information appearing in both images, their correct orientations in ' $3 \mathrm{D}$ space' can be determined. Once known the software is able to derive the wide variety of outputs illustrated in figure 3 . Although drawings can still be generated through manual digitising, NADRAP sought to test and investigate the application of more objective datasets such as Digital Elevation Models (DEM's), in both textured and untextured forms, that can be automatically generated by most modern photogrammetric software using sophisticated pixel correlation algorithms (figure 4). Once generated these can be used to create visualisations and animations of the carvings which convey the nature of the derived datasets very simply and hence are particularly important to the layperson and non-expert user [5].

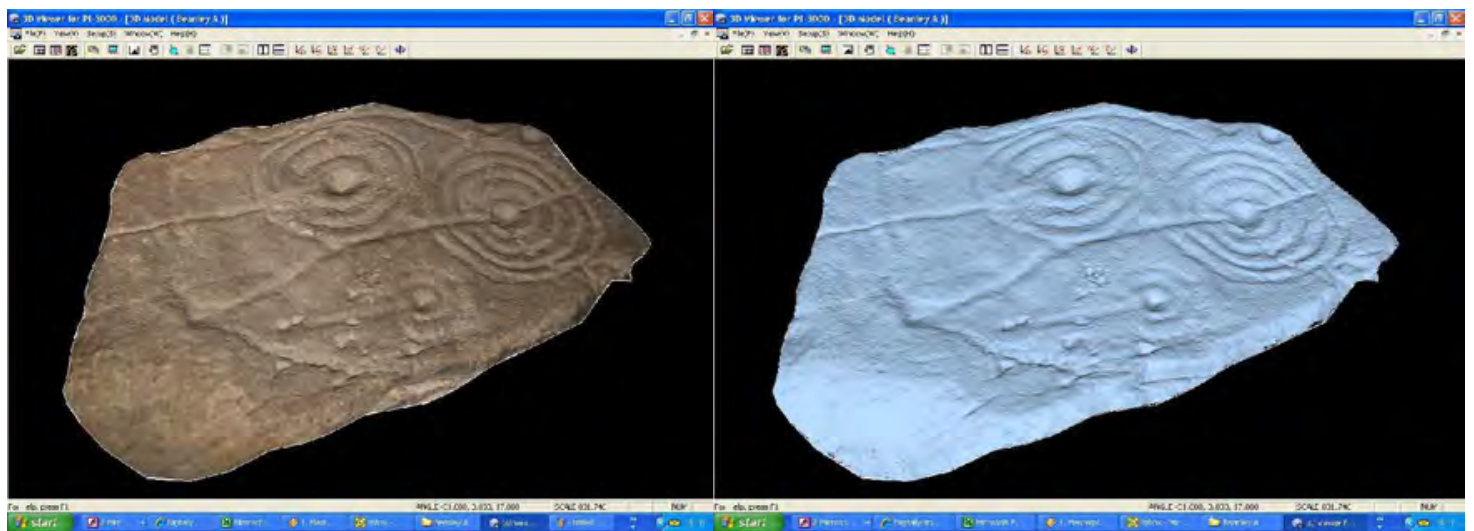

Figure 4. Textured \& Untextured Digital Elevation Model of Beanley Moor Rock Art, Northumberland (courtesy of Richard Stroud, N\&DRAP)

Since NADRAP started in 2004 other commercial digital photogrammetric packages, such as Topcon's PI-3000 'Image Surveying Station', iWitness and most recently Photomodeler 'Scanner', have become available. As well as incorporating the majority of processing tools and accuracy requirements for rock-art recording, their main benefit is cost - typically less than $£ 6,000$. Although this is still relatively expensive for some heritage users, it is a much 'lower-cost' than the high-end photogrammetry packages typically used in other mapping applications.

\section{APPLICATION WITHIN NADRAP PROJECT}

The application of photographic recording was included from the project's start in 2004 and facilitated by the purchase of six Nikon Coolpix 5400 5MPixel digital cameras. Although most of the volunteers, all of diverse ages and technical abilities, could, with time and some basic training, operate and capture an acceptable image of a rock-art panel using such a digital camera, the introduction of stereo-photography and photogrammetry was somewhat unfamiliar. 
Training and education

A number of training sessions followed, run by both the Department of Civil and Building Engineering at Loughborough University and English Heritage's Metric Survey Team, introducing the volunteers to both the concept and components of a photogrammetric survey as well as the practical demonstration of how to capture a stereo-pair - although a simple process which some immediately embraced, not all could engage with this unfamiliar concept. (figure 5)
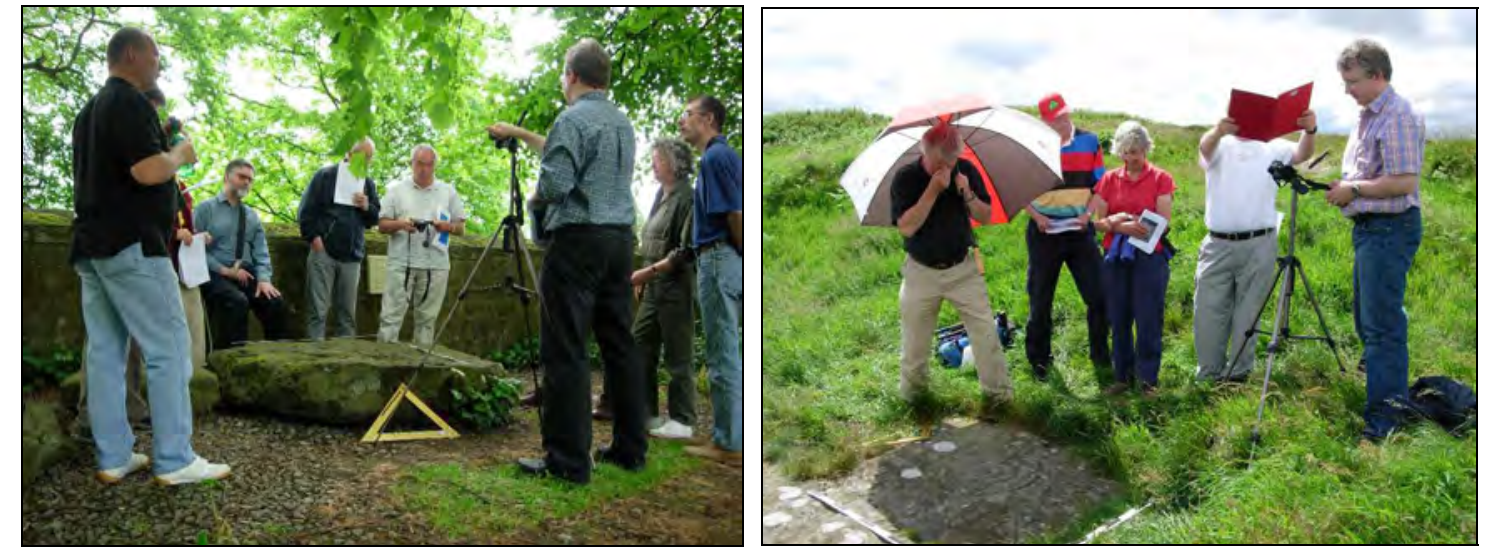

Figure 5. Stereo-photography training on site at Bowes, Co Durham and Doddington, Northumberland (courtesy of Tertia Barnett, RCAHMS)

\section{Processing by volunteers}

The original aim was to concentrate volunteer input into acquiring stereophotography of each known panel alongside the other recording requirements such as narrative and panoramic photography, measured sketches, type, geology and condition assessments. However, whilst demonstrating the full photogrammetric workflow, great interest developed across all teams in potentially processing their own stereophotography in order to generate 3D surface models, orthophotographs and visualizations of rock-art panels themselves using the PI-3000 software. Although English Heritage Metric Survey Team were still researching such 'lower-cost' packages, PI-3000's relative ease of use and ability to import 'consumer-grade' imagery, set it up solely using observed scaled distances, view the stereo-pairs in 3D and, using its own correlation algorithm, generate, output and visualize surface models of the rock carved panel proved very appropriate indeed. A number of PI-3000 licences were subsequently acquired for the project and, after a further period of training and guidance, several of the volunteers became very adept at photogrammetrically processing their own stereo-imagery and able to generate a range of useable data including 3D elevation models (figure 6). 

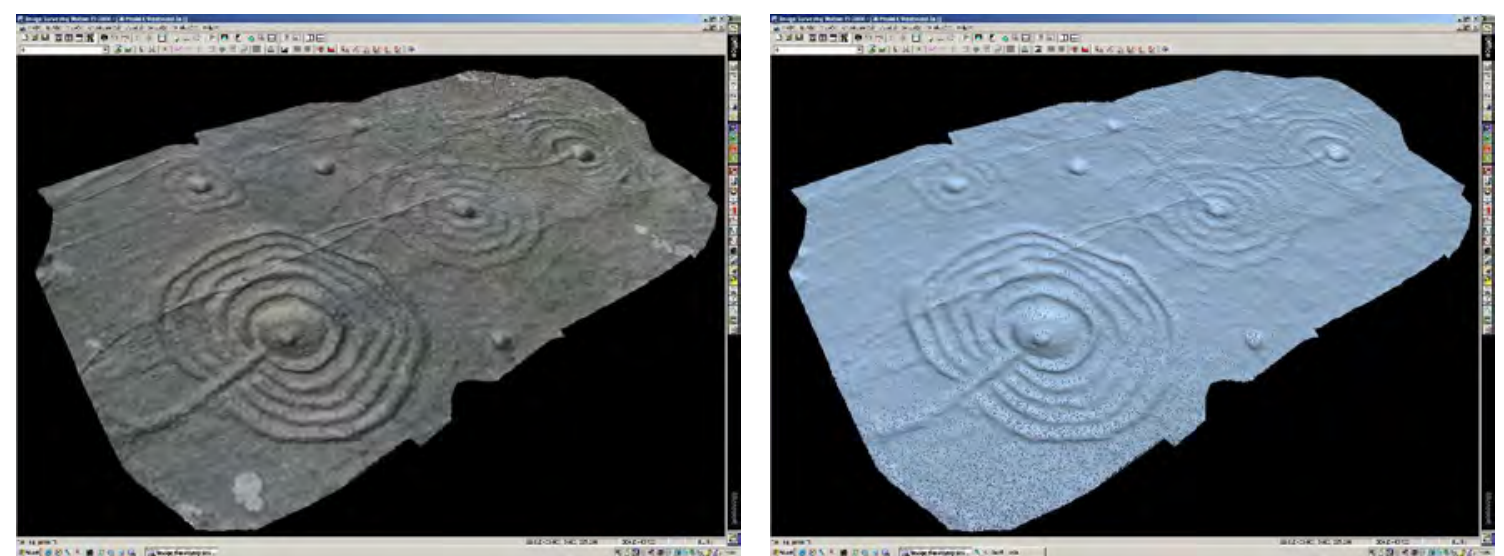

Figure 6. 3D Surface Model of Weetwood 3a rock art panel, Northumberland (courtesy of Joe Gibson, N\&DRAP)

However, the ability to aid expert interpretation of the captured data has to be a key aim of the recording process, as two of the volunteers, Richard Stroud and Joe Gibson, explain:

In addition to $3 D$ viewing and movement of carved panels, which in itself brings a greater reality than standard photography, the ability to remove distracting surface textures to better distinguish and assess artificiality and design components within markings is very useful. Previously undetected motif and design components within markings have been revealed. Cup depth and shape can be better analyzed and measured accurately on screen for comparison purposes. Digital Elevation Models (DEM's) of a reversed surface model can further clarify motif patterns and relationships. Essentially the photogrammetric process allows detailed desk based research on an accurate surface model without intrusion, removal or otherwise endangering easily damaged and irreparable panels. However photogrammetry should not be used in isolation as an interpretive tool for rock art and should be used in conjunction with field visits.

\section{ENGLAND'S ROCK-ART (ERA)}

Subsequently extended to three years, the project was formally completed in July 2008 , by which time a database of over 1,500 known rock art panels located across the two counties of the north-east of England had been created. In addition, the work of NADRAP was combined with the already existing Beckensall Archive to form a new web-site for England's Rock Art, ERA (http://archaeologydataservice.ac.uk/era) alongside publication of an illustrated guidance booklet on Recording, managing and enjoying our carved heritage (figure 7). 

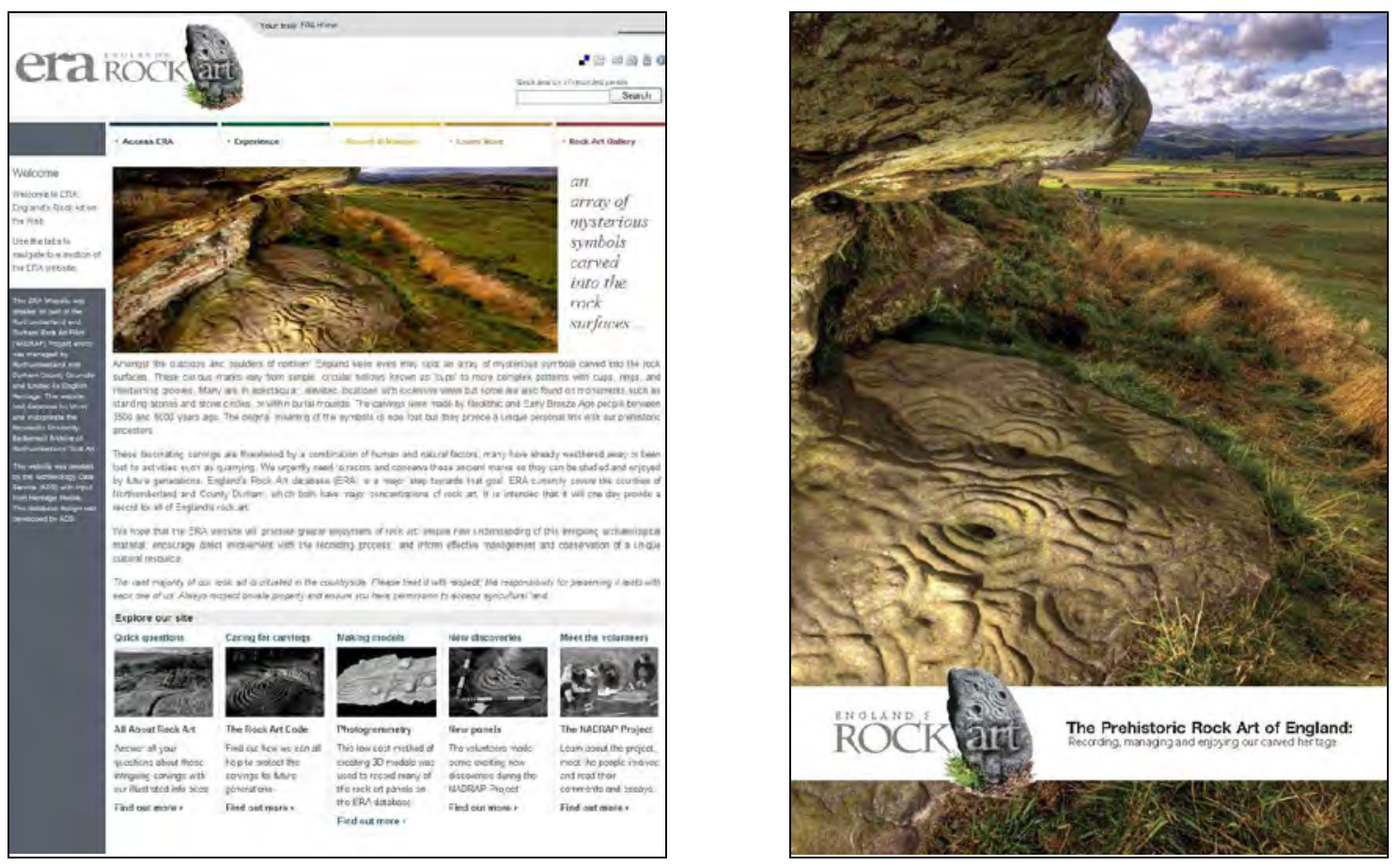

Figure 7. England's Rock Art (ERA) website and guidance booklet (courtesy of NADRAP)

As well as providing a wealth of general information to aid the understanding, valuing, protection and presentation of rock-art in England, the website now provides access to the majority of datasets acquired and generated by the NADRAP volunteers. These include project record sheets, conventional and panoramic photographs, site sketches, archive drawings and all of the associated photogrammetric material consisting of original stereo-pairs and processed 3D Models. By providing access to such material alongside adoption of this new recording technique by the volunteers combined with their own stunning photographic archive, makes England's record of this intriguing prehistoric phenomenon one of the best, and most accessible, in the world [6].

\section{ACKNOWLEDGEMENTS}

The author would like to acknowledge the support of Northumberland and Durham County Councils (Dr Tertia Barnett, (now RCAHMS), Kate Sharp and Sara Rushton), English Heritage (Mick Clowes, David Andrews, Stephen Tovey, Al Oswald, Stewart Ainsworth \& Barney Sloane) and Loughborough University (Jim Chandler and Rene Wackrow) in jointly developing and contributing to the various aspects of the NADRAP project. In addition the contribution of Richard Stroud, Joe Gibson, Andy Curtis, Dave Tuck and all members of the Northumberland and Durham Rock-Art project is recognized for enthusiastically embracing this new recording methodology which together ensured its success. 


\section{References}

[1] ENGLISH HERITAGE. Research Agenda : an introduction to English Heritage's research themes and programme. Edited by Sally Embree and James Stevens. English Heritage, 2005.

[2] BRYAN, P. G. and CHANDLER, J. H. Cost effective rock-art recording within a non-specialist environment. Proceedings of ISPRS 2008, Beijing, China.

[3] CHANDLER, J. H. et al. Metric capabilities of low-cost digital cameras for close-range surface measurement. The Photogrammetric Record. 20(109), March 2005. pp.12-26.

[4] WACKROW, R., CHANDLER, J.H. and BRYAN, P. Geometric consistency/stability of consumer grade digital cameras for accurate spatial measurement. The Photogrammetric Record. 22(118). pp.121-134.

[5] CHANDLER, J.H., BRYAN, P. and FRYER, J.G. The development and application of a simple methodology for recording rock art using consumergrade digital cameras. The Photogrammetric Record. 22(117), 2007. pp.10-21.

[6] ENGLISH HERITAGE. English Heritage research review. Edited by Rowan Whimster and Andrew Sargeant. English Heritage, 2009. 